\title{
Assessing Workers Safety Management Knowledge on Construction Site
}

\author{
Y.D. Mohammed ${ }^{1}$, B.M.T. Shamsul ${ }^{2}$, M.I. Bakri ${ }^{3}$ \\ ${ }^{1}$ Department of Quantity Surveying, Federal University of Technology Minna \\ ${ }^{2}$ Department of Environment and Occupational Health, University Putra Malaysia \\ ${ }^{3}$ Department of Environmental Management, University Putra Malaysia
}

\begin{abstract}
Safety management is associated with the policies, objectives, procedures, methods, roles and functions that aim at controlling hazard and risk in socio-technical systems. Companies that have implemented effective OSH Management system have reported benefit from increase operational efficiency, reduction in insurance cost and improve in workers retention and satisfaction. Many accidents that occur at construction site are due inadequate adherence of workers to work procedures. The awareness and perception of workers toward safety, health and their working environment are important aspect to enhance the building construction to the better condition to the workers. Workers play an important role in accomplishment of the building construction. All these supporting evidence reflects on the needs to study building construction workers knowledge of safety management system. The study is a criteria-based study, in which 24 construction companies were selected for the study The respondent samples used in the study were drawn from the total population of permanent construction workers in the 24 construction companies selected. The total numbers of permanent construction workers in the 24 construction companies are 750 while 254 were selected for the study. The research questionnaires were administered on 254 permanent construction workers within the 24 construction companies in Abuja. The analysis of the questionnaires survey data was undertaken using the statistical package for social science (SPSS) version 20. A reliability test was conducted on the data in order to control error within the data. The Cronbach's Alpha of the two variable data are .853 and .863 respectively and make the data reliable. Correlation analysis was conducted in order to determine the relationship between worker's general knowledge and worker's safety management knowledge and the result was found to be significant $(P<0.005)$. This relationship was modelled using simple linear regression and from the model the result shows that improvement on the worker's safety management system knowledge practice on sites will improves general knowledge among construction workers. Therefore, workers' knowledge of safety management systems significantly influences the overall benefits of safety management system on the construction sites. As such there is need for potential improvement on the knowledge or awareness of the workers to safety management system as perceived from the analysis in order to bring about the expected high performance standard on construction sites.
\end{abstract}

Keywords - Safety Management, Knowledge, Workers, Construction Sites, Improvement.

\section{INTRODUCTION}

Construction industry is vital to the development of any nation, as it strongly contributes to the economic growth of the nation. As such there is need for the industry stakeholders to comply with necessary law and regulations as regard to safety and health of workers. The poor performances record of safety and health in construction industry is because the Occupational Safety and Health (OSH) management system is a neglected area and a function that has not been pursued systematically in the construction industry (Bakri et al. 2006). High rate of injury are primarily due to inadequate or nonexistence of an OSH management. Therefore Davies \& Tomasin (1996) were of the opinion that effective application of OSH Management system can lead to safe construction work and reduce the rate of accidents at construction site.

Occupational safety and health (OSH) is aim at preventing accidents at workplace. Despite the achievement in accidents prevention at most construction sites it has been identified that accidents still exists in construction sites (Levitt \& Samelson, 1993). Safety management relates to the actual practices, roles and functions associated with remaining safe Kirwan, (1998), while Reiman \& Rollenhagen, (2011) safety management is associated with the policies, objectives, procedures, methods, roles and functions that aim at controlling hazards and risk in socio-technical systems.

Researchers like, Shannon, et al., (1996), DePasquale \& Geller, (1999), revealed that organizations with lower accidents rates were characterized by a few of the following factors: safety officers held high rank; management showed personal 
involvement in safety activities; superior training for new employees; frequent training for existing employees; display of safety posters for identifying hazards; well defined procedures for promotion and job placements; daily communication between workers and supervisors about health and safety; frequent safety inspections; higher priority for safety in meetings and decisions concerning work practice; thorough investigation of accidents; more frequent attendance of senior managers at health and safety meetings and empowerment of the workforce.

According to Vredenburgh, (2002), the commitment of the management toward safety management system can manifest itself through job training program, management participation in safety committee, consideration of safety in job design, and review of the pace of work, for example, people working for a supervisor that never mentions safety will make people perceive that safety is not an important issues and they will not place more emphasis on safety at the workplace. Companies that have implemented effective OSH Management system have reported benefit from increase operational efficiency, reduction in insurance cost and improve in workers retention and satisfaction (Bakri, et al., 2006).

The construction workers occupation has been recognized as the most dangerous in term of accidents and fatality rates. Leung, et al. (2010) stated that Construction workers are obliged to work in a poor physical environment, tolerating extreme outdoor temperatures, poor air quality, excessive noise from bulky equipment, various hazards from working at height, poor housekeeping, and exposure to chemicals, and additional factors. Prolonged work under such adverse physical conditions induces stress in construction workers, such as emotional and physical fatigues. Sawacha, et al. (1999); Choudhry and Fang. (2008) working under poor physical environment, which causes discomfort to construction workers, subsequently reduces their attention on safety behaviors.

The concepts of safety culture and safety climate are important contributions from the behavioural and social sciences to workers understanding of occupational safety. Zohar, (1980) defined Organizational Climate, as a summary of molar perceptions that employees share about their work environments. And Neal and Griffin, (2006) defined perceived safety climate as individual perceptions of policies, procedures and practices relating to safety in the workplace". In most construction sites, poor safety awareness, lack of skills, unclear safety responsibilities, boring and simple safety activities or education etc., are major factors affecting workers performances at construction sites.

For example in Malaysia the government have realised the importance of safety management system awareness among the construction workers and through the Construction Industry Development Board (CIDB) together with the National Institute of Occupational Safety and Health (NIOSH) are conducting a safety and health induction program for construction workers or popularly known as Green Card program. This program according to CIDB is an integrated safety and health training program for all construction workers and personnel, which involves the registration and accreditation of construction personnel to enhance safety level at construction site. Similarly the objectives of the program include ensuring that the construction worker is aware of the importance a safe and healthy working place, to provide a basic knowledge on safety and health at construction work site and to inform construction worker of the legal requirement in relation to safety and health (CIDB, 2011).

In a study conducted in Kuala Lumpur and Selangor by Norfairuz, (2003), she among others discovered that awareness on the importance of safety management compliance among many construction workers was low. Safety is reflected in good behaviors. Also according to Hassan, (2007), that many accidents that occur at construction site are due inadequate adherence of workers to work procedures. The awareness and perception of workers toward safety, health and their working environment are important aspect to enhance the building construction to the better condition to the workers themselves (Hassan, 2007). Workers play an important role in accomplishment of the building construction. All these supporting evidence reflects on the needs to study building construction workers knowledge of safety management system.

\section{MATERIALS AND METHODS}

According to Creswell, (2003) that the factor to be consider in selecting the best research methodology should be the influence that such method have on the research problem and objectives. The study largely derives qualitative measure in order to understand the perception of building construction workers towards safety management system. Therefore, qualitative research is used to gain insight into people's attitudes, behaviors, value systems, concerns, motivation, aspiration, culture or lifestyles (safety management system). Also, Denzin \& Lincoln, (2000), claim that qualitative research involves an interpretive and naturalistic approach: "this means that qualitative researcher study things in their 
natural settings, attempting to make sense of or to interpret, and phenomena in terms of the meanings people bring to them". Therefore, qualitative research can be used to inform business decisions policy formation, communication and research focus groups etc. about the extent situation of things (sites condition to the management).

The study is a criteria - based study, in which certain criteria were outline for the selection of the construction companies and their construction workers. Those criteria are:

1. The construction company must be built/civil engineering, construction.

2. The construction firm or company must be more than twenty (20) years in civil/building construction work.

3. The construction workers must at least be with the construction company for not less than fifteen (15) years.

4. His qualification must at least not less than secondary school certificates.

5. The location of the study is Abuja, the Nigeria federal capital.

The target construction companies for this study are large size (with more than 100 workforces) with both permanent and temporary construction workers. The reason was that large construction companies tend to have a high degree of safety awareness of the concepts and notions of management system. This will provide a clear image about safety environment in Abuja, Nigeria

Twenty- five (25) construction companies were identified that meet the study criteria and as such twenty - four (24) of the construction companies were selected for the study. The selection is based on sample selection rules of Krejcie and Morgan, (1970). The respondent samples used in the study were drawn from the total population of permanent construction workers in the 24 construction companies selected for the study. The total numbers of permanent construction workers that meet the study criteria in the 24 construction companies are 750 while 254 were selected for the study following the rules of Krejcie and Morgan, (1970). The research questionnaires were administered on 254 permanent construction workers within the 24 construction companies in Abuja. The analysis of the questionnaires survey data was undertaken using the statistical package for social science (SPSS) version 20. Which is a software package used for statistical analysis. It is now named "IBM SPSS Statistics". It is manufacture in Chicago USA, by SPSS Inc. The SPSS Inc is a leading global manufacturer of software used in data analysis, reporting and modelling.

\section{RESULT AND DISCUSSION}

In social science study, there is need to ascertain the reliability of the data prior to data analysis. As such quality control mechanism is established in order to control error within an existing data in order to make it reliable.

\subsection{Result of Reliability Test}

The table 3.1 below shows the numbers of test conducted on each items and the final number of items that qualified for the analysis.

TABLE 3.1

RESULTS OF RELIABILITY TESTS

\begin{tabular}{|c|c|c|c|c|c|c|c|c|c|}
\hline \multirow[t]{2}{*}{ S/no } & \multirow[t]{2}{*}{ Components } & \multicolumn{2}{|c|}{$1^{\text {st }}$ Test } & \multicolumn{2}{|c|}{$2^{\text {nd }}$ Test } & \multicolumn{2}{|c|}{$3^{\text {rd }}$ Test } & \multicolumn{2}{|c|}{ No. of Items } \\
\hline & & $\alpha$ & $\begin{array}{l}\text { No of } \\
\text { items }\end{array}$ & $\alpha$ & $\begin{array}{l}\text { No of } \\
\text { items }\end{array}$ & $\alpha$ & $\begin{array}{l}\text { No of } \\
\text { items }\end{array}$ & Initial & Final \\
\hline 1 & $\begin{array}{c}\text { Workers General } \\
\text { Knowledge } \\
\text { (WGK) }\end{array}$ & .712 & 7 & .853 & 6 & - & - & 7 & 6 \\
\hline 2 & $\begin{array}{l}\text { Workers Safety } \\
\text { Management } \\
\text { Knowledge } \\
\text { (WSMK) }\end{array}$ & .840 & 11 & .846 & 10 & .863 & 9 & 11 & 9 \\
\hline
\end{tabular}

Source: Researcher analysis

Testing the reliability of the items under workers general knowledge show that one item is deleted as its Cronbach's Alpha if item deleted is greater than initial Cronbach's Alpha (.712). The finial Cronbach's Alpha is .853, and all the six items 
have their Cronbach's Alpha if item deleted less than .853 . The reliability test of workers safety management knowledge show that three test were carried out and three items are deleted as their Cronbach's Alpha if deleted is greater than initial Cronbach's Alpha of .840 and .846 respectively. The finial Cronbach's Alpha is, .863 and all the nine items that qualified for the analysis have their Cronbach's Alpha if item deleted less than .863 .

Correlation analysis was conducted in order to determine the relationship between workers general knowledge and workers safety management knowledge. Table 3.2 shows the result of the correlation analysis.

TABLE 3.2

AVERAGE WORKERS GENERAL KNOWLEDGE (AVGWGK)

\begin{tabular}{|c|c|c|}
\hline Component & $\mathbf{r}$ & $\mathbf{P}$ \\
\hline AVGWSMK & 0.599 & 0.001 \\
\hline
\end{tabular}

listwise $N=254$

Where,

AVGWGK $=$ Average Workers Knowledge

AVGWSMK= Average Workers Safety Management Knowledge

Table 3.2 above reveal the correlation of average workers general knowledge and its correlation is significant at the 0.01 level (2- tailed). $\mathrm{N}=254$. The Pearson's correlation reveals a positive, strong and highly significant relationship between average workers general knowledge and average workers safety management knowledge, The Pearson's correlation ( $r$ ) from table 3.2 is 0.599 while its $\mathrm{P}<0.001$. This means that as the level of general knowledge among construction workers improves there is corresponding improvement on the safety management system knowledge practice on sites or high level of general knowledge among the construction workers improve safety management standard knowledge on site.

Following the existing of positive relationship between the variables, there is a need to predict the outcome of the variables. Therefore, simple linear regression is adopt, the simple linear regression seek to examine the effectiveness of workers safety management standard knowledge on site.

In the simple linear regression model develop, workers general knowledge is the dependent variable while workers safety management knowledge is the independent variable. The result of simple linear regression analysis are presented in Table 3.3 .

TABLE 3.3

MODEL SUMMARY

\begin{tabular}{|c|c|c|c|c|}
\hline Model & R & R Square & Adjusted R Square & Std. Error of the Estimate \\
\hline 1 & $.695^{\mathrm{a}}$ & .483 & .479 & 1.54873 \\
\hline
\end{tabular}

a. Predictors: (Constant): WSMK

b. Dependent Variable: WGK

Table 3.3 shows that $48 \%\left(\mathrm{R}^{2}=48\right)$ of the proportion of variation in workers general knowledge is explained by the variation of level of safety management knowledge of the workers. The $\mathrm{R}^{2}$ adjusted is 0.479 implying that the model explains $47 \%$ of the variation in the workers general knowledge within the population leaving $53 \%$ unexplained. The level of awareness or knowledge of workers on safety management standard on site fails to explain all possible variation in the workers general knowledge. Lack of individual competency understanding of workers and supervisors, ineffectiveness or lack of training and certification of competency, lack of ownership, engagement and empowerment of, communication with responsibility for workers and supervisor are responsible for such knowledge failure.

However, the relationship between workers general knowledge and level of awareness among construction workers of safety management system may not necessarily be entirely linear and therefore, there is need to explore other regression techniques so as to see the amount of variance explained increases. The relationships between the two variables of the model described below. Workers general knowledge, the equation abstracted from Table 3.4 below: 
TABLE 3.4

COEFFICIENT ANALYSIS

\begin{tabular}{|c|c|c|c|c|c|c|c|c|}
\hline \multicolumn{9}{|c|}{ Coefficients $^{\mathrm{a}}$} \\
\hline & \multirow{2}{*}{ Model } & \multicolumn{2}{|c|}{$\begin{array}{l}\text { Unstandardized } \\
\text { Coefficients }\end{array}$} & \multirow{2}{*}{$\begin{array}{c}\text { Standardized } \\
\text { Coefficients } \\
\text { Beta }\end{array}$} & \multirow{2}{*}{$\mathrm{t}$} & \multirow{2}{*}{ Sig. } & \multicolumn{2}{|c|}{$\begin{array}{l}95.0 \% \text { Confidence } \\
\text { Interval for B }\end{array}$} \\
\hline & & B & Std. Error & & & & $\begin{array}{l}\text { Lower } \\
\text { Bound }\end{array}$ & $\begin{array}{l}\text { Upper } \\
\text { Bound }\end{array}$ \\
\hline \multirow{2}{*}{1} & (Constant) & 2.661 & .244 & & 10.888 & .000 & 2.180 & 3.142 \\
\hline & AVGWSMK & .427 & .060 & .360 & 7.135 & .000 & .309 & .544 \\
\hline
\end{tabular}

a.

Dependent Variable: AVGWGK

TABLE 3.5

ANALYSIS OF VARIANCE (ANOVA)

\begin{tabular}{|c|c|c|c|c|c|c|}
\hline \multicolumn{2}{|c|}{ ANOVA $^{\mathbf{a}}$} \\
\hline \multirow{3}{*}{1} & Model & Sum of Squares & df & Mean Square & F & Sig. \\
\hline \multirow{3}{*}{1} & Regression & 8.496 & 1 & 8.496 & 50.902 & $.000^{\mathrm{b}}$ \\
\cline { 2 - 7 } & Residual & 57.080 & 342 & .167 & & \\
\cline { 2 - 7 } & Total & 65.575 & 343 & & & \\
\hline
\end{tabular}

a. Dependent Variable: AVGWGK

b. Predictors: (Constant), AVGWSMK

\section{AVGWGK $=2.661+0.427$ AVGWSMK}

Shows the contribution that workers safety management system knowledge or awareness makes to the workers general knowledge, the result reveals that workers safety management system knowledge contributes additional benefits of unstandardized coefficient $=0.427, \mathrm{t}=7.135$ and $\mathrm{P}<0.005$. In the model the system $(\mathrm{t}=7.135, \mathrm{P}<0.005)$ is a predictor of workers general knowledge and clearly make a great significant contribution to this model. Based on the fact that the $t$ statistic is greater than 2(rule of thumb) is a confirmation of the reliability of the proposed model. The t-test determine whether each $\beta$ differ significantly. The $\beta$ - value has an associated standard error which is used to determine whether or not the $\beta$ - value differ significantly from zero. The $t-$ test associated with $\beta$-value is significant at $P<0.005$. This means that the predictor is making a significant contribution to the proposed model. According to Field, (2005) the smaller the significant value the greater the contribution of the predictor. From the magnitude of the $t$ - statistic, the level of workers knowledge or awareness of safety management system has a great impact on workers general knowledge. As the $\mathrm{P}<0.005$ for F-statistic indicate that the model has a high statistical significance level as shown in table 3.5.

The Table 3.4 indicates further that the independent variable accounts well for the variation in the level of workers safety management knowledge. The positive $\beta$ of 0.427 confirms the positive relationship between workers safety management knowledge and workers general knowledge. This result implies that further implementation of workers safety management knowledge will provide more understanding on workers general knowledge.

Table 3,5 i.e the ANOVA table test shows the importance of the model as a useful predictor of effective workers general knowledge with results of $\mathrm{F}=50.902$ and $\mathrm{P}<0.005$ indicating that the model is making a great significant contribution in predicting the benefit of workers knowledge of safety management system. The existence of large residual sum of squares compare to regression sum of squares indicate that the model do not explain certain variation in the dependent variables. May be other variables that are not in the model are accounting for such variation in the independent variables.

\section{CONCLUSION AND RECOMMENDATION}

The effectiveness of workers general knowledge on site through construction workers' knowledge of safety management system was determined. It was revealed that a reasonable correlation exists between workers' knowledge of safety management system and workers' general knowledge $(r=0.360, \mathrm{P}<0.001)$. This means that workers' general knowledge and workers' knowledge of safety management systems are significantly related. This indicates that as the level of workers' knowledge of safety management system increases, the benefit of the safety management system also increase, i.e improve workers general knowledge. 
The regression models finding indicate that additional improvement on the level of knowledge of safety management system among the workers' will spring up enormous benefit of workers general knowledge on the construction sites. Those are the evidence that improving workers' awareness of safety management system would improve safety and health measures on construction sites. As such workers' knowledge of safety management systems significantly influence the overall benefits of safety management system on the construction sites. The implication of the finding is that while it might be important for contractors to put in place all necessary training relating to safety management system, the training program identified may not bring about the expected high performance standard of safety and health on construction sites. There is need for potential improvement on the knowledge or awareness of the workers to safety management system as perceived from the analysis in order to bring about the expected high performance standard on construction sites. Knowledge or awareness to safety management system is an important consideration to effective safety management system on site as high safety and health performance could improve the organization image through less accident, less absentees of workers from work, less medical bills, etc. The importance of knowledge of safety management system among construction workers is that it will encourage the management to develop and implement an effective safety management system in construction industry. The models could be of help to the stakeholders in the construction industry in developing an effective safety management.

Adequate training of workers is important in order to increase their knowledge or awareness most especially as regard to identifying and minimizing risks/hazards on the sites. Many safety professionals were of the opinion that training and educating construction workers help in reducing cost and save lives. Toole, (2002), had found out that if workers lack proper training on safety and health, the workers' may not be able to recognized potential hazard at the construction sites. This shows that safety and health training plays a significant role in the enhancement of safety in construction. For those contractors that have been beneficiaries of improved safety and health management system in their organization/or construction sites, it is recommended that they should pay more emphasis on meeting the safety requirement standard at construction sites by organizing induction training for new workers, training and educating the old workers, promoting safety measures at the workplace through poster, video and audio media.

\section{REFERENCES}

[1] Bakri, A., Misnan, M. S., Yusof, Z. M., \& Wan, W. Y. (2006). Safety Training For Construction Workers: Malaysian Experience.

[2] Choudhry, R.M. and Fong, D. (2008). Why operatives engage in unsafe work behaviour investigating factors on construction sites. Journal of Safety Science(46), 556 - 584

[3] CIDB. (2011). Newsletter of Construction Industry Development Board Malaysia. Issue 1/2010 .

[4] Creswell, J. (2003). J. 2003. Research Design Qualitative, Quantitative, and Mixed Methods Approaches. Handbook of mixed methods in social \& behavioral research, 209-240.

[5] Davies, V. J., \& Tomasin, K. (1996). Construction Safety Handbook. london: Thomas Telford

[6] Denzin, N. K., \& Lincoln, Y. S. (2000). Handbook of Qualitative Research. London: Sage Publications.

[7] DePasquale, J. P., \& Geller, E. S. (1999). Critical Success Factors for Behavior-Based Safety:: A Study of Twenty Industry-wide Applications. Journal of safety Research, 30(4), 237-249.

[8] Field, A. (2005). Discovering Statistics: Using SPSS for Window

[9] Hassan, Kamal Halil., (2007). Udang-undang Keselamatan Industri di Malaysia. Kuala Lumpur. Dewan Bahasa dan Pustaka.

[10] Kirwan, B. (1998). Safety Management Assessment and Task Analysis: a Missing Link? Safety Management: The Challenge of Change. Elsevier, Oxford, 67, 92.

[11] Krejcie \& Morgan (1970). Determining Sample Size for Research activities, Journal of education and psychological measurement 30, P. $607-610$.

[12] Leung, MY. Chan, YS. \& Yue, KW. (2010). Impacts of Stressors and Stress on the Injury Incidents of Construction Workers in Hong Kong. Journal of Construction Engineering and Management 136 (10): 1093 - 1103.

[13] Levitt, R. E., \& Samelson, N. M. (1993). Construction safety management: London, Wiley.

[14] Neal, A. \& Griffin, M.A. (2006). A study of the lagged Relationships among Safety Climate Safety, Motivation, Safety Behavior and Accidents at the Individual and Group Levels. Journal of Applied Psychology. 91 (4), 946 - 953.

[15] Norfairuz, F. (2003). Amalan Keselamatan di tapak bina: Kajian kes Projek perumahan di sekitar Kuala Lumpur dan Selangor. Fakulti Kejuruteraan Awan, Universiti Teknologi Malaysia. Unpublished thesis.

[16] Reiman., T., \& Rollenhagen, C., (2011). Human and Organizational biases affecting the Management of Safety. Reliability Engineering and System Safety, 96(10), 1263 - 1274.

[17] Sawacha, E. Naoum, S. and Fong, D. (1999). Factors Affecting Safety Performance on Construction sites. International Journal of Project Management. 17,(5). 309 - 315. 
[18] Shannon, H. S., Walters, V., Lewchuk, W., Richardson, J., Moran, L. A., Haines, T., \& D. Verma. (1996). Workplace organizational correlates of lost-time accident rates in manufacturing. American Journal of Industrial Medicine., 29, 258-268.

[19] Toole, T. M. (2002). Construction site safety roles. Journal of Construction Engineering and Management, 128(3), $203-210$.

[20] Vredenburgh, A. G. (2002). Organizational safety: which management practices are most effective in reducing employee injury rates? Journal of safety Research, 33(2), 259-276.

[21] Zohar D. (1980). Safety Climate in Industrial Organizations: Theoretical and Applied, Implications. Journal of Applied Psychology. 65(1):96-102. 